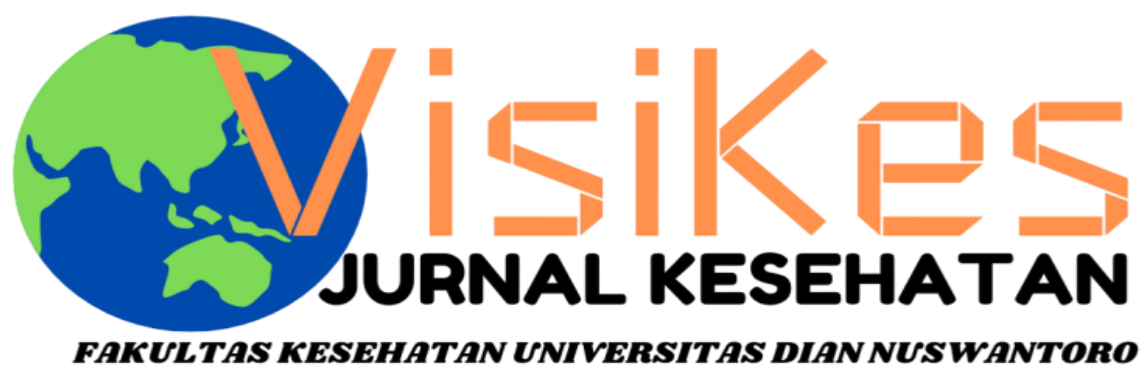

ISSN 1412-3746

FAKULTAS KESEHATAN UNIVERSITAS DIAN NUSWANTORO

Persepsi Mahasiswa Keperawatan Tentang Eskalasi Tenaga Perawat

Rendi Ariyanto Sinanto', Vivi Retno Intening ${ }^{2}$

Risiko kesehatan $\mathrm{Pb}$ dan $\mathrm{Hg}$ pada sayuran di desa Kopeng Kabupaten Semarang

Indira Casheila Anindityo ${ }^{1}$, Nur Endah Wahyuningsih ${ }^{2}$, Yusniar Hanani Darundiati ${ }^{3}$

Analisis Pelaksanaan Program Indonesia Sehat Dengan Pendekatan Keluarga (Pispk) Dalam Capaian Indeks Keluarga

Sehat Di Kabupaten Brebes Tahun 2020 Studi Pada Puskesmas Kluwut Kabupaten Brebes

Rizky Aprilianti Lestari ${ }^{1}$ dr. Antono Suryoputro ${ }^{1}$ Dr. dr. Apoina Kartini. M. Kes ${ }^{1}$

Disiplin Keselamatan dan Kesehatan Kerja melalui pemakaian alat pelindung diri di laboratorium kimia PT Sucofindo

Jakarta

Susan Endah Kartikasari ${ }^{1}$, Tatan Sukwika ${ }^{2}$

Perbedaan Pengetahuan Anemia dan Tablet Tambah Darah (TTD) Sebelum dan Sesudah Pendidikan Kesehatan Melalui

Media Video dan Aplikasi Quizlet

Devita Sari ${ }^{1}$, Gisely Vionalita ${ }^{2}$

Tingkat Pengetahuan Dan Perilaku Mahasiswi Mengenai Legalitas Dan Keamanan Kosmetik

Hani Sri Fitriani, Rizki Siti Nurfitria

Evaluasi Manajemen Dokumen Rekam Medis Di Filing Aktif Rumah Sakit Swasta Kabupaten Semarang

Bobby Anggara Laksana Putra ${ }^{1}$, Retno Astuti Setjaningsih ${ }^{2}$

Tingkat Pengetahuan Gizi Seimbang dan Profil Kesehatan Sopir Bus Antar Kota

Vilda Ana Veria Setyawati ${ }^{1}$, Bayu Yoni Setyo Nugroho ${ }^{1}$

Pengaruh Pengetahuan Dan Motivasi Kerja Terhadap Penerapan Early Warning Score System Di Rsup H Adam Malik Ita Riahna Pinem ${ }^{1}$, Zulfendri', Siti Saidah Nasution ${ }^{3}$

Analisis Penelusuran Masker Sebagai Protokol Kesehatan Saat Pandemi Covid-19 Di Indonesia: Studi Google Trends Ully Febra Kusuma ${ }^{1}$, Nurunnisa Arsyad ${ }^{2}$, Melissa Shalimar Lavinia ${ }^{3}$, Selvia Rahayu ${ }^{4}$, M. Khairul Kahfi , Rizma Adllia Syakurah ${ }^{6}$ Perilaku Hidup Bersih Dan Sehat (Phbs) Dengan Kejadian Sakit Pada Siswa Sekolah Dasar Di Kabupaten Banyumas Windri Lesmana Rubai ${ }^{1}$, Pramesthi Widya Hapsari', Katri Andirini Surijati ${ }^{3}$

Identifikasi Risiko Ganguan Muskuloskletal Pada Pekerja Percetakan Dengan Metode Nordic Body Map

Octavianus Hutapea ${ }^{1}$, Moch.Sahri', Rustam Basuki ${ }^{3}$

Literatur review: Implementasi Bauran Pemasaran 7P Terhadap Tingkat Kepuasan Pasien Di Rumah Sakit

Desi Natalia Marpaung ${ }^{1}$ Ernawaty $^{2}$ Diansanto Prayoga ${ }^{3}$ Syifa'ul Lailiyah $^{4}$

Kelengkapan Informasi Medis Untuk Mendukung Kodefikasi Penyakit Jantung Guna Mewujudkan Kualitas Data Informasi Medis Di Rumah Sakit Islam Sultan Agung Semarang

Dyah Ernawati ${ }^{1}$, Ratna Rifatul Ulya ${ }^{2}$, Arif Kurniadi ${ }^{3}$

Kajian Faktor Kendala Dokter Tidak Menggunakan Aplikasi Wifi Tb Di Kota Semarang

Arif Kurniadi', Evina Widianawati2, Dyah Ernawati ${ }^{3}$

Analisis Pelaksanaan Program Penanggulangan Tuberkulosis Paru Di Puskesmas Purwoyoso Kota Semarang

Nahari Ratu Cempaka Wilis ${ }^{1}$ Hardi Warsono ${ }^{2}$ M. Sakundarno Adi ${ }^{3}$

Hubungan Penggunaan Alat Pelindung Diri (Apd) Dengan Kadar Sgot Dan Sgpt Dalam Darah Pada Petani Padi

Iga Maliga, Rafi'ah

Faktor Risiko Kejadian Stunting Pada Balita di Wilayah Kerja Puskesmas Pandan Kabupaten Sintang

${ }^{1}$ Agustini Elisabet, ${ }^{2}$ Elvi Juliansyah

Peran Suami Dan Petugas Kesehatan Dengan Deteksi Dini Kanker Serviks

Christina Leasa, ${ }^{1}$ Mariene Wiwin Dolang

Analisis Penerapan Protokol Kesehatan terhadap Tingkat Kepatuhan Pada Pekerja informal Selama Pandemi Covid-19

MG Catur Yuantari ${ }^{1}$, Enny Rachmani ${ }^{2}$, Eti Rimawati ${ }^{1}$, Sri Handayani ${ }^{1}$, Edi Jaya Kusuma ${ }^{2}$

Peran Pengawas Minum Obat Dan Pendampingan Berobat Ulang Dengan Keberhasilan Pengobatan Tb Paru

Taswin $^{\left.1^{*}\right)}$, (zan $^{1)}$, Wahyuddin $^{1)}$, Dahmar ${ }^{1)}$

Faktor Determinan Sosial Dan Gambaran Kejadian Post Traumatic Syndrome Disorder (Ptsd) Pasca Banjir Di Dki Jakarta

Dan Bekasi Tahun 2020

Thresya Febrianti ${ }^{1}$, Nurfadhillah ${ }^{2}$, Mitha Nurhjanah ${ }^{3}$, Tiara Kautsa Aliefya ${ }^{4}$

Perbedaan Pola Makan Pada Balita Stunting Dan Tidak Stunting Di Kecamatan Teon Nila Serua (Tns) Kabupaten Maluku Tengah

Trixie Leunupun ${ }^{1}$, Ani Margawati' ${ }^{2}$ Annastasia Ediati ${ }^{3}$

Gambaran Pengelolaan Rekam Medis Rawat Inap Di Rsud Syekh Yusuf Kab. Gowa Tahun 2019

Zilfadhilah Arranury*, Surahmawati, Muhammad Rusmin, Tri Addya Karini, Dian Rezki Wijaya, Ranti Ekasari, Jihan Sulfitri

Analisis Risiko Kesehatan dalam Pemanfaatan Kemball Limbah Sludge Industri Makanan PT. X

Sri Slamet Mulyati ${ }^{1}$, Fajar Sihite ${ }^{2}$ 


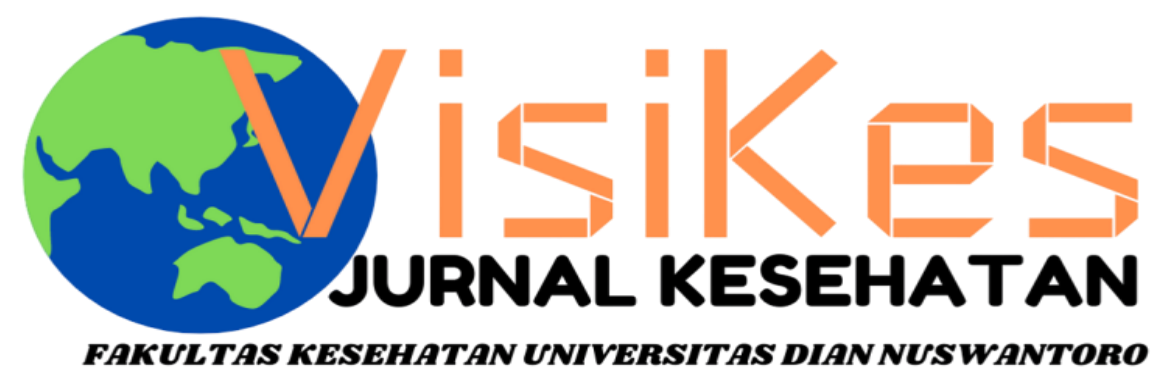

Volume 20, Nomor 1, April 2021

\section{Ketua Redaksi}

Dr. Drs. Slamet Isworo, M.Kes

\section{Penyunting}

Enny Rachmani, SKM, M.Kom, Ph.D

Fitria Wulandari, SKM, M.Kes

\section{Sekretariat}

Lice Sabata, SKM

Desain dan Layout

Puput Nur Fajri, SKM

\section{Alamat Redaksi}

Fakultas Kesehatan Universitas Dian Nuswantoro Jl. Nakula I No. 5-11 Semarang Telp/fax. (024) 3549948

email : visikes@fkes.dinus.ac.id

website $\quad$ : http://publikasi.dinus.ac.id/index.php/visikes/index

VisiKes diterbitkan mulai Maret 2002

Oleh Fakultas Kesehatan Universitas Dian Nuswantoro 


\title{
Persepsi Mahasiswa Keperawatan Tentang Eskalasi Tenaga Perawat
}

\author{
Rendi Ariyanto Sinanto ${ }^{1}$, Vivi Retno Intening ${ }^{2}$ \\ ${ }^{1}$ Magister Kesehatan Masyarakat Universitas Ahmad Dahlan \\ 2STIKES Bethesda Yakkum Yogyakarta \\ E-mail : rendisinanto@gmail.com
}

\begin{abstract}
According to the Ministry of Health, the number of graduate nurses per year is 46,865 people, the national need per year is 24,825 people, and the excess production of nurses is 11,067-22,060 per year. The increase in educational institutions has an impact on increasing graduates, nursing students are a generation of nurses, so this situation is very worrying for the nursing profession. The purpose of this study was to determine the perceptions of Nursing Diploma 3 students of STIKES Bethesda Yakkum Yogyakarta about the impact of increasing the nursing workforce. This study used a qualitative design with a phenomenological approach. The instrument used was a human instrument with an interview guide. The population in this study were 61 D3 Nursing student semester VI, the sample was taken by purposive sampling as many as 5 participants. The analysis used was content analysis, and the triangulation technique used was source triangulation. The results of this study indicate that the participants know the current condition of nurses, the increase in the number of nurses makes the participants disappointed with the lecture process that has been undertaken, the educational institutions have increased so that graduates have increased, but the absorption is not optimal. This situation will result in unemployment of nurses and nurses not working according to their profession. Participants hope that the government will open up jobs so that nurses can contribute to the country in health development. Even though the participants knew about the escalation of nurses, the participants were optimistic, confident in their abilities, would be entrepreneurial in the health sector, and knowledge could be useful for their surroundings.
\end{abstract}

Keywords: Nursing Students, Nurse Personnel, Nurse Escalation

\section{PENDAHULUAN}

Menurut Undang-Undang Nomor 38 Tahun 2014 Tentang Keperawatan, menyatakan bahwa keperawatan adalah bentuk pelayanan professional yang menjadi bagian integral dari pelayanan kesehatan, didasarkan pada ilmu dan kiat keperawatan. Pelayanan yang diberikan berbentuk pelayanan biologis, psikologis, sosial, spiritual yang komprehensif, ditujukan pada individu, keluarga dan masyarakat, baik sehat maupun sakit yang mencakup seluruh proses kehidupan manusia ${ }^{1}$. Perawat merupakan salah satu elemen garda terdepan dan ujung tombak dalam pembangunan kesehatan serta penanganan masalah terkait kesehatan di Indonesia, perawat merupakan tenaga kesehatan dengan jumlah terbanyak di Indonesia, tahun 2014 Persatuan Perawat Nasional Indonesia telah mengumpulkan data di 15 provinsi terdapat 11.300 perawat, kebanyakan telah lebih dari lima tahun bekerja sebagai perawat honor dan sukarela di instansi pelayanan kesehatan milik pemerintah².

Menurut Kementerian Kesehatan dari data rencana pengembangan tenaga kesehatan tahun 2011-2025 Jumlah lulusan institusi pendidikan keperawatan per tahun 46.865 orang terdiri dari pendidikan diploma 34.480 orang, profesi ners 12.385 orang, kelulusan Uji Kompetensi Nasional per tahun sebanyak 35.892 orang, terdiri dari Pendidikan Diploma 25.086 orang, dan Profesi Ners 10.806 orang, kebutuhan nasional per tahun 
24.825, dan kelebihan produksi perawat adalah 11.067-22.060 per tahun ${ }^{3}$.

Sesuai pemberitaan dari Tribunnews Jakarta, Kamis, 16 Maret 2017 Persatuan Perawat Nasional Indonesia (PPNI) melakukan aksi demonstrasi di Gedung DPR $\mathrm{RI}$ agar diangkat menjadi Pegawai Negeri Sipil (PNS). PPNI bersama sejawat anggotanya yaitu perwakilan perawat honor dan tenaga kerja sukarela yang diikuti dari perwakilan seluruh provinsi di Indonesia lebih dari 4000 perawat akan memperjuangkan nasib dengan melakukan aksi ke DPR RI terutama komisi II DPR RI untuk menyampaikan aspirasi dan tuntutan. Tuntutannya adalah agar ada perubahan regulasi yaitu Undang-Undang Aparatur Sipil Negara agar dapat menerima PNS dari perawat yang honor atau tenaga kerja sukarela tanpa syarat dan menghargai lama masa kerja yang telah diemban di instansi pemerintah ${ }^{4}$.

Sesuai data yang diperoleh dari Ristekdikti (2016), bahwa sekolah tinggi keperawatan sangat meningkat di Indonesia, sekolah tinggi keperawatan yang terakreditasi dan terdaftar mengikuti uji kompetensi berjumlah 416 untuk pendidikan diploma, sedangkan untuk pendidikan profesi ners berjumlah 257 institusi ${ }^{5}$. Peneliti melakukan studi dokumentasi pada Prodi Diploma 3 Keperawatan STIKES Bethesda Yakkum Yogyakarta pada tahun 2018, didapatkan bahwa jumlah lulusan mahasiswa diploma 3 keperawatan dalam 3 tahun terakhir adalah 297 orang. Tahun akademik 2015/2016 berjumlah 143 mahasiswa, tahun 2016/2017 berjumlah 93 mahasiswa dan tahun 2017/2018 berjumlah 59 mahasiswa. Sesuai data tersebut dapat menjadi bukti bahwa sekolah tinggi perawat setiap tahun meluluskan tenaga perawat, sehingga menambah jumlah kompetitor bagi mahasiswa yang akan lulus nantinya

Sesuai dengan fenomena di atas, sangat menyedihkan sekaligus mengkhawatirkan bagi mahasiswa keperawatan di Indonesia. Kondisi ini akan menyebabkan peningkatan tenaga kerja perawat karena minim peluang kerja di dalam negeri, pengangkatan pegawai negeri sipil terbatas dan pendidikan tinggi keperawatan yang menciptakan tenaga perawat setiap tahun, namun tidak semuanya dapat diserap, selain itu tenaga sukarela dan honorer semakin bertambah setiap tahun. Mengingat mahasiswa keperawatan adalah generasi penerus tenaga perawat di masa akan datang, maka peneliti merasa tertarik untuk melakukan penelitian terkait bagaimana persepsi mahasiswa Diploma 3 Keperawatan STIKES Bethesda Yakkum Yogyakarta tentang dampak eskalasi tenaga kerja perawat.

\section{METODE PENELITIAN}

Desain penelitian yang digunakan adalah desain kualitatif dengan pendekatan fenomenologi yaitu memberikan deskripsi atau interpretasi terkait persepsi mahasiswa Diploma 3 Keperawatan tentang dampak eskalasi tenaga kerja perawat ${ }^{6}$. Penelitian ini bertujuan untuk mengetahui persepsi mahasiswa Diploma 3 Keperawatan STIKES Bethesda Yakkum Yogyakarta tentang dampak eskalasi tenaga kerja perawat. Dalam 
penelitian ini terdapat variabel tunggal yaitu persepsi mahasiswa Diploma 3 Keperawatan STIKES Bethesda Yakkum Yogyakarta tentang dampak eskalasi tenaga kerja perawat. Penelitian ini dilakukan di STIKES Bethesda Yakkum Yogyakarta pada tanggal 22 Februari 2019 sampai 27 Februari 2019. Teknik sampel yang digunakan adalah purposive sampling ${ }^{7}$. Sampel yang digunakan yaitu mahasiswa Diploma 3 Keperawatan berjumlah lima partisipan. Instrumen yang digunakan yaitu human instrument dengan pedoman wawancara, dan teknik triangulasi yang digunakan adalah triangulasi sumber. Kemudian analisis yang digunakan peneliti yaitu analisis isi, serta peneliti menggunakan kelaikan etik (Ethical Clearance) dalam penelitian ini dengan Nomor: 933/C.16/FK/2019.

\section{HASIL}

Penelitian ini melibatkan lima orang partisipan Diploma 3 Keperawatan semester VI, dengan jenis kelamin perempuan sebanyak empat partisipan, dan jenis kelamin laki-laki satu partisipan, kemudian terdapat tiga partisipan berusia 20 tahun, dan dua partisipan berusia 21 tahun. Berdasarkan hasil wawancara didapatkan 44 kode, enam kategori, dan dua tema. Hasil penelitian ini diuraikan sebagai berikut.

Persepsi partisipan tentang eskalasi tenaga kerja perawat yaitu seluruh partisipan memiliki pengetahuan tentang adanya peningkatan tenaga perawat saat ini, kemudian minat siswa untuk menjadi perawat tinggi, sarjana tanpa profesi banyak dan bekerja tidak sesuai disiplin ilmu, serta tenaga perawat semakin meningkat sedangkan lowongan rumah sakit sedikit, yang mengakibatkan kesempatan kerja kurang.

"Profesi perawat saat ini mungkin gimana ya, ya udah bagus sih, cuman mungkin ada beberapa, seperti penghargaan yang belum layak dan mungkin persaingan untuk kerja banyak ya, juga banyak orang-orang awam menganggap buruk tentang perawat gitu ada juga" (Partisipan 1).

"Mungkin banyak ya sekarang lulusan perawat, juga yang minat perawat banyak, apalagi S1, S1nya banyak, dan rumah sakit itu setiap hari kan gak, setiap tahun kan gak menerima sebanyak lulusan itu, pasti hanya sebagian yang diterima, dan nasib yang tidak diterima ini mungkin bisa meneruskan ke jenjang selanjutnya atau mereka lebih memilih bekerja yang tidak pada bidangnya, misalnya perawat S1 tapi dia gak ners dia milih jadi pegawai bank, jadi kan itu udah terlalu menyimpang ya kayak gitu sih" (Partisipan 2). "Tau, setelah saya lulus dari SMA itu e, prodi yang dipilih itu kebanyakan perawat" (Partisipan 3).

"Iya mengetahui" (Partisipan 4).

"Kalau dilihat sih peningkatan itu mungkin, peningkatan tenaga perawat" (Partisipan 5).

Partisipan menanggapi situasi peningkatan tenaga perawat yang terjadi, yaitu seluruh partisipan sangat menyayangkan proses yang dijalani, kemudian merasa sia-sia dan kecewa, sementara itu lulusan perawat meningkat sedangkan penyerapan tidak maksimal, kemudian lapangan kerja kurang, penghargaan dan perlakuan belum layak. 
Partisipan mengatakan seharusnya ada lapangan kerja karena perawat sangat dibutuhkan dan semua partisipan mengatakan tetap akan berusaha.

"Ya sayang aja gitu udah sekolah tapi gak terserap gitu kan, mungkin juga karena rumah sakitnya juga kurang gitu" (Partisipan 1).

"Sebenanya gapapa, malah lebih baik kan jika tenaga medis itu atau tenaga perawat itu semakin banyak, tetapi juga harus diimbangi dengan lapangan pekerjaan yang memadai dan juga penghargaan terhadap profesi tersebut" (Partisipan 2).

"Ya tadi kan saya udah bilang bahwa setelah aku lulus SMA itu banyak teman milih prodi perawat, dan sekarang lulusan perawat yang lulus setiap tahun lebih banyak dari pada yang dibutuhkan itu ya sebenarnya agak kaget juga sih, terus lagian D3 juga kan beberapa tahun kedepan akan dihapuskan, makanya saya ingin alih jenjang agar saya tetap bisa bekerja, nah sebenarnya itu ada rasa sedikit gimana ya, kita itu ibaratnya sekolah, disekolahin biar bisa meningkatkan kesehatan di negara berkembang seperti ini tetapi ketika kita sudah dibekali ilmu yang cukup sudah siap bekerja tapi gak ada lahan itu ya sedikit kecewa, dan akhirnya banyak kan perawat yang lari dan gak bekerja pada passionnya, ya begitu ada rasa kecewa, tetapi saya tetap akan berusaha kalo bisa akan tetap bekerja dibidang kesehatan" (Partisipan 3).

"Hm harusnya lebih banyak lapangan pekerjaan, karena perawat menurut saya paling dibutuhkan di negeri ini kan" (Partisipan 4).
"Pandangan saya sih menanggapinya, harusnya ini, harusnya lebih ada lagi peluang buat tenaga perawat dipekerjakan, terus pandangan saya sih kurang ini ya, kurang maksimal, banyak yang sekolah perawat tapi sedikit yang diserap" (Partisipan 5).

Penyebab eskalasi tenaga kerja perawat menurut partisipan yaitu karena standar yang tinggi dalam selektif untuk rekruitmen kerja, kemudian banyak perawat tanpa Surat Tanda Registrasi (STR) dan tidak kompeten. Selain itu adanya pembatasan tenaga kerja, pengangguran meningkat. Kemudian penyebab lainnya yaitu tingginya keyakinan dan harapan terhadap profesi perawat ditandai dengan peminat menjadi perawat meningkat, dan institusi penyelenggara pendidikan meningkat sehingga menyebabkan lulusan juga meningkat.

"E menurut aku itu mungkin dari pembatasan tenaga kerjaan, terus mungkin dari setiap rumah sakit itu punya aturan masing-masing, ada yang kalo ada kan yang minta IPK itu minimal 3 gitu, ada juga mungkin lulusan perawat cuman belum punya STR gitu kan itu juga banyak gitu, mungkin itu sih yang membuat banyak yang gak keserap" (Partisipan 1).

"Mungkin karena tenaga perawat itu sudah banyak orang berpikiran sudah pasti diterima kerja, sudah pasti mendapat kerja, dan kalaupun tidak dapat kerja ilmunya itu bisa diterapkan dimanapun. Karena selagi masih ada manusia pasti orang-orang itu akan butuh tenaga perawat, juga dengan lulus tapi mereka tidak memenuhi kriteria untuk bekerja di rumah 
sakit atau suatu institusi juga bisa, misal apa ya kompetensinya kurang memadai, etikanya kurang, ya seperti itu" (Partisipan 2).

"Karena kalo menurut saya mungkin asumsi saya sih, kalo menurut saya pada dulunya itu tenaga kesehatan kan sangat dibutuhkan dengan jumlah tenaga kesehatan yang sedikit, nah ketika kita sudah tau banyak tenaga kesehatan yang dibutuhkan kan kita ee berpikir oh aku pilih prodi itu aja siapa tau nanti masa depanku lebih bagus, pas kita udah punya pemikiran kayak gitu tapi ternyata malah tenaga kesehatan yang tersedia lebih banyak dari pada tenaga yang dibutuhkan" (Partisipan 3).

"Banyak ini banyak universitas-universitas yang dadakan bikin STIKES kesehatankesehatan itu terlalu banyak menurut saya" (Partisipan 4).

"Em kalau mau dilihat-liat sih banyak juga kampus-kampus yang ada jurusan perawat, kalau dilihat dari kampus STIKES saja sudah banyak dan kalau dilihat secara keseluruhan Indonesia juga pasti banyak, dan juga kan kalo kita mau kerja kan pasti dilihat dari ini keterampilan, nah mungkin yang tidak terserap itu kurang memiliki keterampilan" (Partisipan $5)$.

Kemudian persepsi partisipan tentang dampak eskalasi tenaga kerja perawat yaitu, menurut semua partisipan dampak yang muncul adalah perawat yang menganggur meningkat, kemudian adanya kekecewaan lulusan perawat terhadap proses yang telah dijalani, sehingga kedepannya akan mempunyai resiko terjadi penurunan minat menjadi perawat, selain itu kurangnya lapangan kerja menyebabkan lulusan perawat bekerja tidak sesuai disiplin ilmu.

"Ya mungkin banyak penganguran, e itu aja sih" (Partisipan 1).

“Jadi tadi tenaga perawat juga tidak terserap banyak, juga banyak pengangguran, juga nanti suatu saat akan turun peminatan terhadap profesi perawat" (Partisipan 2).

"Ya dampaknya gimana ya sia-sia gitu kita udah sekolah, udah tau, udah punya bekal, udah punya ilmu kayak gini tapi gak bisa mengaplikasikan kayak sayang aja ilmunya, terus nanti kalau kita sudah bekerja terus dituntut untuk sekolah lagi ya ekonomi buat sekolahnya, terus otak buat berpikirnya, waktunya itu sih" (Partisipan 3).

"Ada lapangan pekerjaan nanti kurang kan, banyak pengangguran, secara garis besar itu sih" (Partisipan 4).

"Dampaknya ya sudah jelas pasti sia-sia sekolahnya, terus kalau apalagi ya mungkin pengangguran" (Partisipan 5).

Faktor yang mempengaruhi persepsi partisipan untuk tetap ingin menjadi perawat yaitu secara keseluruhan partisipan merasa optimis dan semangat, yakin akan kemampuan diri, dan akan berwirausaha bidang kesehatan, kemudian ilmu dapat bermanfaat untuk lingkungan sekitar.

"Ya kalau kan kalau lulusan perawat itu gak harus jadi perawat juga kan, kan bisa aja kayak membuka apa misalnya kayak dia mau cari surat izin-izin gitu kan bisa buka kayak apa namanya klinik diabetes kayak gitu atau apa khusus kayak perawatan-perawatan luka terus 
pelatihan-pelatihan kayak keperawatan gitu kan kita nanti bisa buka sendiri" (Partisipan 1). "Karena pada prinsip awalnya tadi memang ya saya sudah nyaman dengan fase ini dengan proses ini, ternyata jadi perawat itu gak mudah dan juga jadi perawat itu ada prosesnya sendiri dan banyaklah di luar sana jika kita emang kompeten jika kita etikanya baik akan banyak yang menerima, pun ketika tidak diterima di suatu rumah sakit atau apapun kita bisa menjadi perawat home care kita bisa punya kompetensi tersendiri dan kita bisa bergunalah dimana saja" (Partisipan 2).

"Ya karena ibaratnya saya tidak akan membuang, tidak akan menyia-nyiakan ilmu yang sudah saya dapatkan selama ini, dan yang terpenting ilmu yang sudah saya miliki ini ingin saya aplikasikan didalam kehidupan saya sehari-hari membantu saudara saya, saudarasaudara kita semua yang membutuhkan, gak harus bekerja, tapi kita berbagi, kita sharing kepada teman-teman kita, kepada tetangga kita itu sudah jauh lebih bermanfaat" (Partisipan 3).

"Ya karena untuk kesehatan itu nomor satu menurut saya, kesehatan kan e tetap kesehatan keluarga itu nomor satu, jadi tetap dipertahankan, kan gak mau kalau tiba-tiba di rumah ada yang sakit gitu kan telat penolongan kita hanya nangis-nangis ah gimana caranya kita tetap sehat bersama bareng keluarga, kalo saya gitu” (Partisipan 4). "Soalnya kan yang butuh perawat gak hanya di negeri sendiri, jadi masih bisa ada peluang di Negara luar, e menguntungkan juga sih, kalaupun aku gak bisa bekerja sebagai perawat, tapi kan setidaknya punya ilmu, jadi bisa digunakan dilingkungan sendiri meskipun tidak bekerja di rumah sakit" (Partisipan 5).

Harapan partisipan tentang dampak eskalasi tenaga kerja perawat yaitu seluruh partisipan mengatakan agar perawat dapat meningkatkan kemampuan diri, dan meningkatkan mutu pelayanan, kemudian terbukannya lowongan kerja agar perawat dapat berkontribusi untuk negara sehingga perawat sejahtera untuk menuju derajat kesehatan masyarakat yang optimal.

"Ya harapan saya sih, e terbukanya lowongan pekerjaan, terus ee semakin diperhatikanlah lulusan perawat ini, kan bisa membantu juga, e harapan saya institusi tidak mempersulit, Mempersulit maksudnya kayak yang setau saya nih setau saya ya, saya dengar-dengar itu misalnya kayak yang lulusan D3 tahun kemarin ini itu belum menjalani ujian kompetensi, berarti kan otomatis mereka belum mendapatkan STR, nah itu kayaknya sih yang jadi faktor ee kendala untuk bekerja, dan mungkin pemerintah lebih memperhatikan tenaga keperawatan itu, terus bisa buka lapangan pekerjaan untuk perawat, pokoknya mendukung aja gitulah" (Partisipan 1).

"Harapannya lapangan pekerjaan akan semakin banyak, penghargaan juga semakin meningkat, juga kita harus sadar bahwa kita harus selalu meningkatakan kemampuan kita setiap saat, harapan saya ya profesi perawat ini bisa memberikan kontribusi yang banyak buat negara lah intinya" (Partisipan 2).

"Ya kalo bisa harapan saya itu untuk lulusanlulusan perawat itu ya diberi lahan lah, maksudnya gak harus PNS lah, di RS swasta 
pun bisa yang penting kita bisa meningkatkan kesehatan masyarakat, kalau kesehatan bagus mereka bisa bekerja dengan baik kan mendorong untuk kemajuan negara juga" (Partisipan 3).

“Untuk pemerintah bukalah apa, lowongan pekerjaan. sebenarnya banyak tapi pemerintah tuh menyaringnya terlalu ketat gitu loh, bikin susah betul, jadi agak di longgarkanlah" (Partisipan 4).

"Harapan saya sih kalau semakin banyak mahasiswa yang kuliah di jurusan keperawatan artinya harus tersedia juga lapangan pekerjaan untuk mereka, dan harapan saya sih saya bisa bekerja, bisa dipergunakan ilmunya" (Partisipan 5).

\section{PEMBAHASAN}

Persepsi partisipan tentang eskalasi tenaga kerja perawat, yang pertama yaitu terkait pengetahuan partisipan tentang kondisi profesi perawat saat ini. Persepsi adalah suatu proses yang melibatkan pengetahuan yang telah dimiliki, yang disimpan didalam ingatan untuk memperoleh dan menginterpretasikan stimulus (rangsangan) yang diterima oleh indra manusia ${ }^{8}$. Menurut Notoatmodjo (2012), pengetahuan merupakan hasil pengindraan terhadap suatu objek melalui indera manusia ${ }^{9}$. Sesuai dengan teori tersebut, maka sejalan dengan hasil penelitian yang ditemukan peneliti bahwa seluruh partisipan memiliki pengetahuan tentang kondisi keperawatan saat ini yaitu peningkatan tenaga perawat yang tidak terserap lapangan kerja.

Hasil penelitian tersebut sejalan dengan data menurut Kementerian Kesehatan bahwa kebutuhan nasional pertahun adalah 24.825 orang, sedangkan kelebihan produksi perawat yaitu 11.067 sampai 22.060 orang per tahun. Kemudian terdapat juga hasil penelitian menurut Santy (2012), yang mengatakan bahwa meningkatnya penyelenggara pendidikan tinggi keperawatan menyebabkan lulusan perawat bertambah ${ }^{10}$. Hal ini didukung dengan hasil triangulasi sumber dengan Ketua Kelas Mahasiswa Diploma 3 Keperawatan semester VI, bahwa tenaga perawat memang banyak, dan setiap lahan kerja yang ada tidak menerima semua tenaga yang ada. Sesuai data dari Kementerian Kesehatan per Desember 2019, perawat menduduki peringkat pertama jumlah tenaga kesehatan yang didayagunakan di fasilitas pelayanan kesehatan seluruh Indonesia sebesar 376.136 orang, hal ini mengindikasikan bahwa perawat merupakan jumlah tenaga kesehatan terbanyak saat ini ${ }^{11}$.

Berikutnya terkait tanggapan partisipan tentang situasi peningkatan tenaga perawat yang terjadi. Seluruh partisipan sangat menyayangkan proses yang dijalani, kemudian merasa sia-sia dan kecewa, sementara itu lulusan perawat meningkat sedangkan penyerapan tidak maksimal, kemudian lapangan kerja kurang, penghargaan dan perlakuan belum layak. Menurut Donsu (2017), persepsi seseorang dipengaruhi oleh faktor eksternal seperti informasi yang diperoleh, dan faktor internal seperti perasaan, sikap, harapan, serta motivasi. Sesuai teori tersebut maka sejalan dengan hasil yang peneliti temukan bahwa seluruh partisipan mengetahui tentang situasi peningkatan tenaga perawat. 
Berdasarkan hasil triangulasi sumber dengan Ketua Kelas Mahasiswa Diploma 3 Keperawatan semester VI, memiliki persamaan dengan jawaban partisipan yaitu merasa sedih terhadap situasi peningkatan tenaga perawat yang terjadi.

Selain itu partisipan memiliki harapan tentang adanya lapangan kerja, menurut Donsu (2017), hal ini dipengaruhi oleh faktor internal yaitu harapan. Kemudian terkait semua partisipan akan tetap berusaha, hal tersebut sesuai dengan faktor internal yaitu motivasi partisipan sendiri. Motivasi merupakan sesuatu yang mendorong seseorang untuk bertingkah laku dalam mencapai tujuan tertentu ${ }^{12}$. Berdasarkan uraian tersebut maka dapat disimpulkan bahwa partisipan memiliki tujuan untuk bekerja sehingga partisipan berpendapat akan tetap berusaha. Kemudian terkait persolaan penghargaan pada perawat yang belum layak, hal tersebut sesuai dengan penelitian Husin, Huda, dan Ranisa (2016), bahwa manajemen harus melakukan evaluasi terkait sistem penggajian yang belum sesuai ${ }^{13}$. Apabila sistem pengupahan baik maka akan memberikan kepuasan pada perawat yang berdampak pada pelayanan yang baik juga, hal ini sejalan dengan penelitian yang mengatakan bahwa terdapat hubungan antara pembayaran dengan kepuasan perawat ${ }^{14}$.

Penyebab eskalasi tenaga kerja perawat menurut partisipan sebagai berikut. Partisipan 1 mengatakan bahwa penyebab peningkatan tenaga perawat yaitu karena standar yang tinggi dalam selektif untuk rekruitmen kerja, salah satunya terkait Surat Tanda Registrasi.
Kemudian banyak perawat yang tidak memiliki Surat Tanda Registrasi (STR), sehingga menyebabkan perawat tidak terserap lapangan kerja. Hal ini sejalan dengan penelitian Sirait (2020), bahwa banyak perawat belum mendapatkan pekerjaan karena tidak memiliki Surat Tanda Registrasi ${ }^{15}$. Hasil penelitian tersebut didukung dengan UndangUndang No 38 tahun 2014 Tentang Keperawatan pasal 18 yang menyatakan bahwa, perawat dapat melaksanakan praktik keperawatan profesional apabila memiliki Surat Tanda Registrasi. Hasil penelitian Kumaladewi (2018), menunjukan bahwa jumlah pelamar perawat yang memenuhi kualifikasi sedikit dan hasil tes tidak sesuai yang diharapkan ${ }^{16}$. Hasil penelitian tersebut memiliki persamaan dengan pernyataan partisipan bahwa rekruitmen kerja memiliki standar yang tinggi.

Partisipan 2 mengatakan penyebab meningkatnya tenaga perawat karena keyakinan serta harapan terhadap profesi perawat yang tinggi ditandai dengan peminat menjadi perawat meningkat, hal ini sejalan dengan penelitian Pramudita (2016), bahwa ada hubungan antara minat terhadap motivasi melanjutkan ners ${ }^{17}$. Terdapat penelitian yang sama menurut Fadlilah dan Komala (2020), yaitu minat melanjutkan profesi ners dalam kategori tinggi ${ }^{18}$. Selain itu juga adanya perawat yang tidak kompeten sehingga perawat yang menganggur meningkat. Sejalan dengan pernyataan partisipan 2 tersebut, maka sesuai dengan Undang-Undang No 38 Tahun 2014 yang menyatakan bahwa untuk mengukur kompetensi perawat maka 
dilakukan uji kompetensi. Apabila kompetensi seorang perawat tidak memadai maka tidak akan lulus uji kompetensi, sehingga menyebabkan peningkatan perawat yang tidak terserap lapangan kerja karena tidak kompeten. Mendukung hal tersebut terdapat penelitian menurut Prihandhani dan Gandari (2019), yang mengatakan bahwa kinerja perawat sangat berhubungan dengan kompetensi dan beban kerja perawat ${ }^{19}$.

Kemudian partisipan 3 mengatakan penyebabnya yaitu lapangan pekerjaan tidak diimbangi dengan jumlah lulusan perawat pertahun. Menurut Penelitian Santy (2012), salah satu penyebab peningkatan tenaga kerja perawat adalah tempat bekerja terbatas, dan perawat lemah berbahasa asing. Kemudian hasil penelitian tersebut didukung dengan data dari Kementerian Kesehatan tentang rencana pengembangan tenaga kesehatan tahun 2011-2025, bahwa jumlah lulusan institusi pendidikan per tahun 46.865, dan kebutuhan nasional per tahun 24.825, data ini memiliki persamaan dengan jawaban dari partisipan 3 yaitu lapangan pekerjaan tidak diimbangi dengan jumlah lulusan perawat setiap tahunnya.

Selain itu partisipan 4 dan partisipan 5 mengatakan bahwa penyebab eskalasi tenaga perawat yaitu karena institusi penyelenggara pendidikan keperawatan meningkat sehingga menyebabkan lulusan juga meningkat. Hal tersebut sesuai dengan data dari Ristekdikti tahun 2016, bahwa sekolah tinggi keperawatan sangat meningkat di Indonesia, untuk pendidikan diploma berjumlah 416 , dan profesi ners berjumlah 257 institusi.
Berdasarkan data tersebut maka mempunyai persamaan dengan jawaban partisipan bahwa institusi pendidikan keperawatan meningkat di Indonesia.

Kemudian terkait persepsi partisipan tentang dampak eskalasi tenaga kerja perawat, didapatkan bahwa menurut semua partisipan dampak yang muncul adalah perawat yang menganggur meningkat, kemudian adanya kekecewaan lulusan perawat terhadap proses yang telah dijalani, sehingga kedepannya akan mempunyai resiko terjadi penurunan minat menjadi perawat, selain itu kurangnya lapangan kerja menyebabkan lulusan perawat bekerja tidak sesuai disiplin ilmu. Hasil triangulasi sumber dengan Ketua Program Studi Diploma 3 Keperawatan STIKES Bethesda Yakkum Yogyakarta juga menyebutkan bahwa apa yang disampaikan oleh partisipan itu benar dan sah-sah saja berpikir seperti itu, tetapi perawat atau lulusan keperawatan nantinya harus berani keluar dari zona nyaman. Hal tersebut sejalan dengan studi dari Lestari (2014), yang mengatakan bahwa perawat harus mampu untuk membuka diri serta wawasan agar lebih luas memandang suatu fenomena ${ }^{20}$.

Berikutnya faktor yang mempengaruhi persepsi partisipan tetap ingin menjadi perawat yaitu partisipan merasa optimis dan semangat, yakin akan kemampuan diri, dan akan berwirausaha bidang kesehatan, kemudian ilmu dapat bermanfaat untuk lingkungan sekitar. Donsu (2017), mengatakan bahwa persepsi seseorang dipengaruhi oleh faktor internal dan faktor eksternal. Sesuai 
hasil yang peneliti dapatkan, diketahui bahwa partisipan 2 dan partisipan 3 memiliki motivasi yaitu semangat, kemudian partisipan juga optimis serta yakin akan kemampuan diri. Hal ini didukung dengan teori menurut Donsu (2017), yang mengatakan bahwa perasaan, sikap, keinginan, harapan, dan motivasi merupakan faktor internal yang mempengaruhi persepsi seseorang.

Sesuai hasil triangulasi sumber dengan dosen bagian kemahasiswaan STIKES Bethesda Yakkum Yogyakarta, didapatkan bahwa STIKES Bethesda Yakkum Yogyakarta memiliki kerja sama dengan berbagai rumah sakit serta beberapa yayasan sehingga lulusan perawat dari STIKES Bethesda Yakkum Yogyakarta selalu berpeluang terserap lapangan kerja setiap tahun. Sesuai uraian tersebut maka dapat disimpulkan bahwa partisipan memiliki motivasi dan rasa optimis karena institusi STIKES Bethesda Yakkum Yogyakarta memiliki afiliasi dengan beberapa rumah sakit dan yayasan untuk rekruitmen kerja setiap tahun.

Kemudian partisipan 1, partisipan 4, dan partisipan 5 mengatakan bahwa akan berwirausaha dibidang kesehatan, hal ini didukung dengan penelitian dari Cahyaningrum (2013), bahwa perawat perlu mengembangkan potensi agar mampu mandiri sehingga dapat berwirausaha dibidang kesehatan ${ }^{21}$. Mendukung hasil tersebut terkait berwirausaha bidang kesehatan, maka sesuai dengan ruang lingkup profesi perawat salah satunya adalah home health care yaitu memberikan pelayanan dirumah serta memberikan pelayanan secara luas ${ }^{22}$. Selain itu partisipan juga mengatakan agar ilmu dapat bermanfaat untuk lingkungan sekitar. Hasil tersebut sejalan dengan teori menurut Donsu (2017), yang mengatakan bahwa faktor eksternal yang mempengaruhi persepsi yaitu latar belakang keluarga, informasi yang diperoleh, pengetahuan, dan kebutuhan sekitar. Sesuai dengan teori tersebut, maka memiliki persamaan dengan jawaban dari ketiga partisipan yaitu ilmu dapat bermanfaat untuk lingkungan sekitar.

Harapan partisipan tentang dampak eskalasi tenaga kerja perawat yaitu seluruh partisipan mengatakan agar perawat dapat meningkatkan kemampuan diri, dan meningkatkan mutu pelayanan, kemudian terbukannya lowongan kerja agar perawat dapat berkontribusi untuk negara sehingga tercapainya perawat sejahtera untuk menuju derajat kesehatan masyarakat yang optimal. Hal ini sesuai dengan penelitian Siregar dan Antoni (2017), bahwa tenaga kerja perawat sukarela mengharapkan perhatian dari instansi dan pemerintah ${ }^{23}$. Sesuai triangulasi sumber dengan ketua kelas mahasiswa Diploma 3 Keperawatan semester VI STIKES Bethesda Yakkum Yogyakarta, didapatkan bahwa harapan terkait situasi peningkatan tenaga perawat adalah pemerintah lebih bisa melihat profesi perawat sebagai profesi yang penting dalam pembangunan kesehatan dan memberikan lapangan kerja. Sesuai hasil tersebut maka dapat disimpulkan bahwa perawat mengharapkan peluang kerja agar dapat memberikan pelayanan kesehatan kepada masyarakat. 


\section{SIMPULAN DAN SARAN}

Partisipan memiliki pengetahuan tentang kondisi profesi perawat saat ini yaitu mengetahui tentang adanya peningkatan tenaga perawat, minat siswa untuk menjadi perawat tinggi, sarjana tanpa profesi banyak dan bekerja tidak sesuai disiplin ilmu, terkait peningkatan tenaga kerja partisipan menyayangkan proses yang dijalani, kemudian terasa sia-sia dan kecewa. Persepsi partisipan tentang penyebab eskalasi tenaga kerja perawat adalah standar yang tinggi dalam selektif rekrutmen untuk bekerja, banyak perawat tanpa Surat Tanda Registrasi (STR) dan tidak kompeten, pengangguran meningkat, minat menjadi perawat meningkat, serta institusi penyelenggara pendidikan meningkat menyebabkan lulusan juga meningkat.

Persepsi partisipan tentang dampak eskalasi tenaga kerja perawat yaitu adanya peningkatan perawat yang menganggur, kemudian adanya kekecewaan lulusan perawat terhadap proses yang dijalani, kemudian kedepannya akan terjadi penurunan minat menjadi perawat, dan kurangnya lapangan kerja akan menyebabkan lulusan perawat bekerja tidak sesuai disiplin ilmu. Tetapi partisipan tetap ingin menjadi perawat serta memiliki semangat dan optimisme yang tinggi serta yakin akan kemampuan diri, dan akan berwirausaha bidang kesehatan, sehingga ilmu dapat bermanfaat untuk lingkungan sekitar.

Saran bagi Organisasi Profesi Persatuan Perawat Nasional Indonesia untuk turut memperjuangkan nasib perawat baik yang belum mendapatkan pekerjaan dan yang sudah mendapatkan pekerjaan tetapi belum mendapatkan penghargaan yang layak. Bagi STIKes Bethesda Yakkum Yogyakarta agar memberikan seminar tentang wirausaha, dan mengembangkan mata kuliah entrepreneurship lebih optimal kedepannya, kemudian untuk pemerintah membuka lapangan kerja kepada perawat tanpa ada diskriminasi kebijakan terhadap profesi perawat, dan yang terakhir kepada tenaga perawat agar meningkatkan mutu pelayanan kesehatan, menjunjung tinggi sumpah profesi, membuka wawasan dan berani keluar dari zona nyaman agar dapat berkembang, sebab perawat bukan hanya bekerja dirumah sakit tetapi memiliki ruang lingkup yang cukup luas.

\section{DAFTAR PUSTAKA}

1. Undang-Undang Nomor 38 Tahun 2014.

2. Kemenkes. Pusat Data dan Informasi Situasi Tenaga Keperawatan [Internet]. BPPSDM. 2017 [cited 2017 Mar 17]. Available from: www.pusdatin.kemenkes.go.id

3. Kemenkes. Rencana Pengembangan Tenaga Kesehatan Tahun 2011-2025 [Internet]. 2011. Available from: https://www.google.com/url?sa=t\&sourc e=web\&rct=j\&url=http://www.who.int/wor kforcealliance.

4. Herudin. Kamis Besok, Ribuan Perawat akan Demo ke DPR Tuntut Diangkat Jadi PNS [Internet]. Tribunnews. 2017 [cited 2018 Mar 7]. Available from: https://www.tribunnews.com/nasional/20 17/03/15/kamis-besok-ribuan-perawat- 
akan-demo-ke-dpr-tuntut-diangkat-jadipns?page $=2$

5. Ristekdikti. Uji Kompetensi Ners Serentak di Seluruh Indonesia [Internet]. 2016 [cited 2018 Apr 28]. Available from: https://www.google.co.id/url?sa=t\&sourc e=web\&rct=j\&url=http://belmawa.ristekdi kti.go.id/2016/04/04/uji-kompetensi-ner

6. Notoatmodjo. Metodologi Penelitian Kesehatan. Jakarta: Rineka Cipta; 2012.

7. Nursalam. Metodologi IImu Keperawatan Pendekatan Praktis. Edisi 4. Jakarta: Salemba Medika; 2016.

8. Donsu JDT. Psikologi Keperawatan. Yogyakarta: Pustaka Baru Press; 2017.

9. Notoatmodjo S. Promosi Kesehatan dan Perilaku Kesehatan. Jakarta: Rineka Cipta; 2012.

10. Santy WH. Menghadapi Peluang Kerja Perawat Di Kancah. 2012;

11. Kemenkes. Data SDM Kesehatan Yang Didayagunakan Di Fasilitas Pelayanan Kesehatan (Fasyankes) di Indonesia [Internet]. Badan PPSDM Kesehatan. 2019 [cited 2021 Mar 7]. Available from: http://bppsdmk.kemkes.go.id/info_sdmk/ info/index?rumpun=9

12. Hamzah U. Teori Motivasi dan Pengukurannya. Jakarta: Bumi Aksara; 2011.

13. Husin, Huda .A R. . Kepuasan Kerja Perawat. 2016; Available from: http://download.garuda.ristekdikti.go.id/a rticle.php?article $=999460 \& \mathrm{val}=13960 \&$ tit $l e=K E P U A S A N$ KERJA PERAWAT

14. Sirait E, Pertiwiwati E, Herawati $H$. Faktor-Faktor Yang Mempengaruhi
Kepuasan Kerja Perawat Di Ruang Rawat Inap Rsud Haji Boejasin Pelaihari. Dunia Keperawatan. 2017;4(1):14.

15. Sirait R. Meningkatnya Jumlah Pengangguran Pada Profesi Perawat: Surat Tanda Registrasi (STR). 2020;1-7.

16. Kumaladewi A. Efektivitas Rekrutmen dan Seleksi dalam Memenuhi Kebutuhan Tenaga Perawat di RSIA Muslimat Jombang. Parsimonia. 2018;5(1):29-40.

17. Pramudita FA. Hubungan Antara Minat dan Persepsi Terhadap Motivasi Melanjutkan Ners Pada Mahasiswa Keperawatan Universitas Muhammadiyah Surakarta [Internet]. Universitas Muhammadiyah Surakarta; 2016. Available from: https://core.ac.uk/download/pdf/1486118 28.pdf

18. Fadlilah $\mathrm{M}$, Komala T. HUBUNGAN DUKUNGAN ORANG TUA DENGAN MINAT MELANJUTKAN PROFESI NERS MAHASISWA S1. J 'Aisyiyah Med. 2020;5:253-64.

19. Prihandhani IGAAS, Gandari NKM. Hubungan kompetensi, motivasi dan beban kerja perawat pelaksana dalam penerapan asuhan keperawatan dengan kinerja perawat Di Ruang Rawat Inap Badan Rumah Sakit Umum Tabanan. J Keperawatan BSI. 2019;VII(1):1-5.

20. Lestari TRP. Harapan atas profesi keperawatan di indonesia. Kajian. 2014;Vol. 79(1):51-68.

21. Cahyaningrum I. Perspektif Perawat Terhadap Karakteristik Wirausaha. In: Prosiding Konferensi Nasional PPNI 
Jawa Tengah [Internet]. Semarang: Lembaga Penelitian dan Pengabdian Kepada Masyarakat Unibersitas Muhammadiyah Semarang; 2013. p. 225-8. Available from: https://jurnal.unimus.ac.id/index.php/psn 12012010/article/view/881/935

22. Nisya Rifiani HS. Prinsip-Prinsip Dasar Keperawatan. Jakarta: Dunia Cerdas;
2013.

23. Siregar Hotma Royani AA. Motivasi dan Harapan Perawat Menjadi Perawat Tenaga Kerja Sukarela. Jurnnal Kesehat Ilm Indones [Internet]. 2017;2(3). Available from: https://jurnal.stikesaufa.ac.id/index.php/health/article/view/1 09 